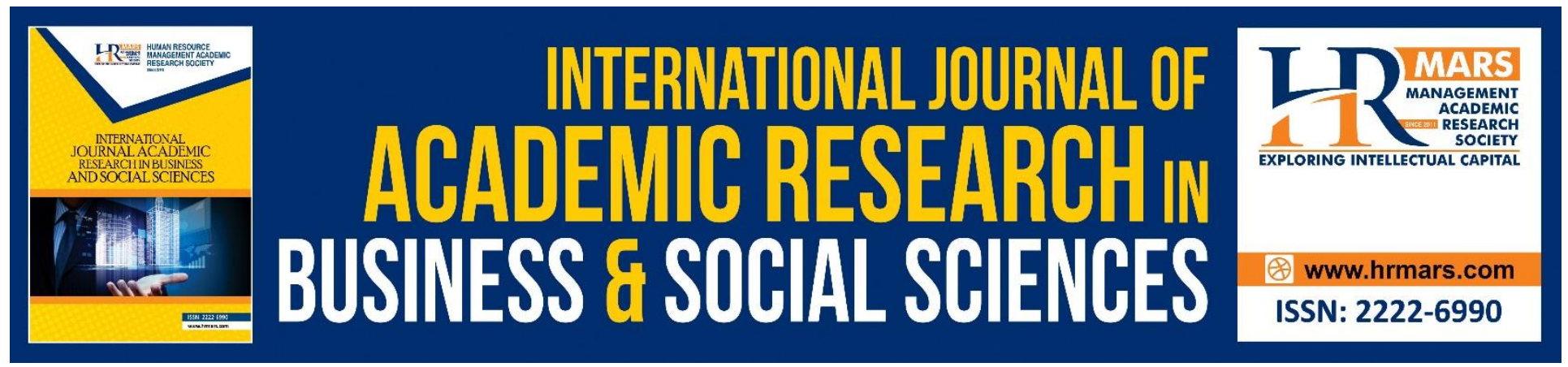

\title{
Data Centre Colocation: Challenges and Opportunities in Private, Public and Hybrid Cloud for Businesses
}

Nurul Fadhlin Mohd Nazim, Siti Noor Hidayah Senapi, Saiful Farik Mat Yatin, Nurussobah Hussin, Nor Hasliza Ngah @ Muhammad, Norazam Abd Manan

To Link this Article: http://dx.doi.org/10.6007/IJARBSS/v9-i6/5977

DOI: $10.6007 /$ IJARBSS/v9-i6/5977

Received: 11 April 2019, Revised: 15 May 2019, Accepted: 09 June 2019

Published Online: 29 June 2019

In-Text Citation: (Nazim et al., 2019)

To Cite this Article: Nazim, N. F. M., Senapi, S. N. H., Yatin, S. F. M., Hussin, N., Muhammad, N. H. N. @, \& Manan, N. A. (2019). Data Centre Colocation: Challenges and Opportunities in Private, Public and Hybrid Cloud for Businesses. International Journal of Academic Research in Business and Social Sciences, 9(6), 624-639.

Copyright: (C) 2019 The Author(s)

Published by Human Resource Management Academic Research Society (www.hrmars.com)

This article is published under the Creative Commons Attribution (CC BY 4.0) license. Anyone may reproduce, distribute, translate and create derivative works of this article (for both commercial and non-commercial purposes), subject to full attribution to the original publication and authors. The full terms of this license may be seen at: http://creativecommons.org/licences/by/4.0/legalcode

Vol. 9, No. 6, 2019, Pg. 624 - 639

Full Terms \& Conditions of access and use can be found at http://hrmars.com/index.php/pages/detail/publication-ethics 


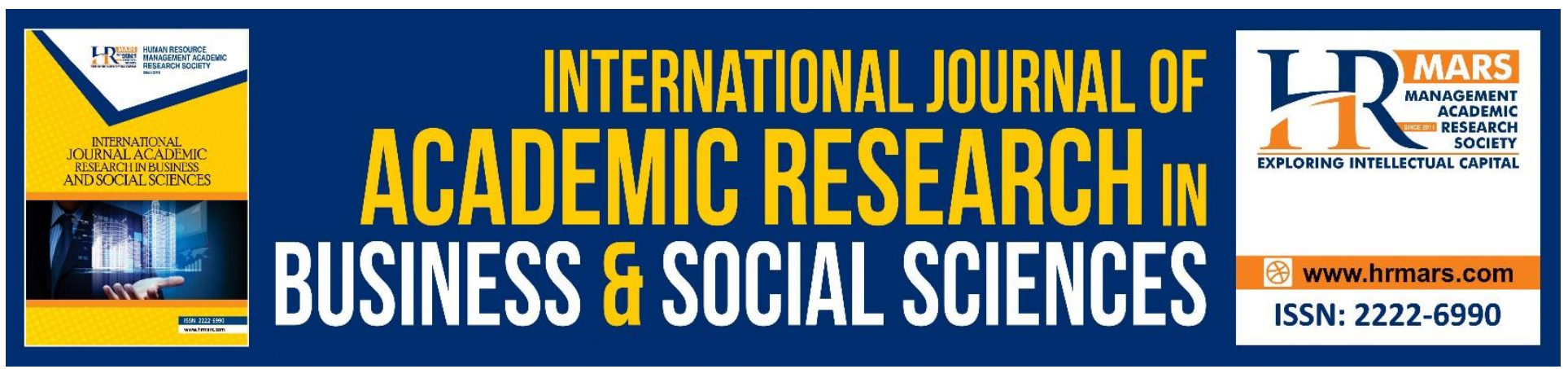

\title{
Data Centre Colocation: Challenges and Opportunities in Private, Public and Hybrid Cloud for Businesses
}

\author{
${ }^{1}$ Nurul Fadhlin Mohd Nazim, ${ }^{1}$ Siti Noor Hidayah Senapi, 1,2Saiful \\ Farik Mat Yatin, ${ }^{1}$ Nurussobah Hussin, ${ }^{1}$ Nor Hasliza Ngah @ \\ Muhammad, ${ }^{1}$ Norazam Abd Manan \\ ${ }^{1}$ Faculty of Information Management, Universiti Teknologi MARA (UiTM) Selangor, Malaysia \\ ${ }^{2}$ Members of Advanced Analytics Engineering Center (AAEC), UiTM \\ Email: farik@salam.uitm.edu.my
}

\begin{abstract}
Data center colocation service offers businesses rental space infrastructure for equipment rack, network servers, cooling, power, physical security and internet bandwidth; with 24/7 technical supervision for close to $100 \%$ uptime promise. Enterprise in-house data centres are getting increasingly expensive to build and maintain. Many colocation providers also provide managed hosting services and Business Process Outsourcing among other services. Data centre operators face challenges from public cloud providers, and suggestions are being explored for opportunities. This paper presents 3 cloud deployment models; namely private cloud, public cloud and hybrid cloud. The three-layer model of cloud computing; namely Infrastructure as a Service (laaS), Platform as a Service (PaaS) and Software as a Service (SaaS) is also introduced and briefly discussed. Colocation players with a global footprint are seeing the benefits of offering business platform which can adapt to customer demand and making the most out of the cloud deployment a model.
\end{abstract}

Keywords: Data Centre, Colocation, Hybrid Cloud, Business Process Outsourcing, Disaster Recovery

\section{Introduction}

Data centre colocation is a method through which an organisation can lease a sizeable office space, network or Internet bandwidth and other resources within an active data centre instead of building its own data centre. It facilitates the sharing of existing pool of data centre real estate to be used for arrangement and hosting data centre services for external or retail customers/organisations. Data centre colocation is primarily provided by data centre or IT service providers. Typically, data centre colocation is arranged within a data centre colocation facility. Such a feature is useful to a data centre 
having ample, unused floor space available for rental. The owner of the data centre colocation facility provides the floor space, cooling, power and physical security whereas the consumer brings in its own servers, storage and/or applications. Data centre colocation primarily enables organisations to arrange a data centre facility without the need to buy or manage it.

Frost and Sullivan (2017) mentions that data center colocation players in Asia Pacific include market leaders such as NTT Communications (Japan), China Telecom (China), Singtel (Singapore), and Telstra (Australia). Closer to the Malaysia market, companies such as AIMS, VADS, and Exabytes are pretty much dominating vendors in this sector.

\section{Challenges to Modern Colocation Business}

Regardless of industry or business sector, $\mathrm{ClOs}$ and technology leaders face many challenges when it comes to IT infrastructure management. They have to constantly develop suitable strategies and implement appropriate solutions to overcome a myriad of company-wide demands.

\section{Physical Space}

The requirement for physical space is particularly important to corporations, especially to those collecting significant amount of data. The scale of big data calls for exponential growth of storage solution and queries. It is becoming increasingly challenging to fulfil this demand of physical space.

\section{Power and Cooling Efficiency}

The huge data centres operated by global corporations today utilise enormous amounts of power. The need to invest in additional power solution is growing in importance to accommodate the growing demands in data centre infrastructure. The requirement for more redundant power sources, Uninterruptible Power Supplies (UPS) and backup generators is enigma to the business. And since equipment in the data centre must be kept cool, provisioning adequate cooling facilities is also a challenge in this business.

\section{Reliability}

In order to maintain the degree of reliability of the critical applications and services, the business must deliver as close as $\mathbf{1 0 0 \%}$ of uptime. However, in order to achieve that, building an in-house, purpose-built data centre that has all the required infrastructure to afford such uptime, is getting prohibitively expensive.

\section{Scalability and Future Proofing}

It is increasingly difficult for in-house data centre to allow for scalability and guarantee futureproofing. When businesses grow, the data centre must be able to deal with varying volumes, need for speed and multiplicities of big data requests. Future requirements need to be considered while implementing any infrastructure.

\section{Performance}

In order to stay ahead in this relentless era, businesses want innovative and highly adaptive solutions. The demands for high performance data centre is increasing, in-line with the increasing network 
INTERNATIONAL JOURNAL OF ACADEMIC RESEARCH IN BUSINESS AND SOCIAL SCIENCES Vol. 9, No. 6, June, 2019, E-ISSN: 2222-6990 (C) 2019 HRMARS

bandwidth, volumes and server workload from year to year. Businesses need to empower their employee in order to expect higher efficiency and productivity using the latest virtualization technologies and installing higher-density racks,

\section{Compliance and Security}

Modern data center has to comply industry standard to stay on top of security, physically and virtually. Data center facilities has to be constantly locked, guarded and monitored by surveillance equipment. The organizations must follow the latest protocols and security techniques to ensure data remains protected and its reliability is kept intact.

\section{To Buy or to Build?}

Colocation solutions does not only drive real business value and improve efficiency and productivity within each business unit but also do so as cost-effectively as possible. When CIOs think to expand their data center operation, more businesses are expressing a preference for third-party colocation solutions instead of building their own data center. This one-sided decision is not surprising due to the need to keep everything relatively low cost, agile, secure and dynamic.

\section{A Shift to Colocation}

Recent studies by various technology market research firms shows that respondents said they were more likely to shift to a colocation solution as their business grows in the future. In the study, respondents who are currently using both colocation and managed hosting are more likely to move towards further colocation than managed hosting. Unsurprisingly, cost still remains an important factor in any decision, higher than level of service or performance.

\section{Quality of Product and Service More Important than Price}

Quality of colocation services is gaining in importance when considering an external IT service. Cost have less of an effect on the decision making when growth of business and quality of support becomes more prevalent to the data centre needs offered to the organisation. It shows that the future for colocation service industry remains positive.

\section{Business Process Outsourcing (Bpo)}

The broad definition of Business Process Outsourcing (BPO) is often described as a subsection of outsourcing that entails the hiring out of the processes and functions of a certain professional process to a third-party service provider. Kimmel (2015) says that BPO is generally classified into back-office outsourcing (internal business functions such as finance and accounting or Human resources), and front office outsourcing, (customer-related services such as contact centre services.

Business processes that are normally outsourced are information technology-based, referred to as ITES-BPO, where ITES stands for Information Technology Enabled Service. Business process outsourcing helps boosts the flexibility of a company in several aspects:

- it helps a company to be more adaptable in reacting to transformations

- the company can concentrate on its primary capabilities 
INTERNATIONAL JOURNAL OF ACADEMIC RESEARCH IN BUSINESS AND SOCIAL SCIENCES

Vol. 9, No. 6, June, 2019, E-ISSN: 2222-6990 @ 2019 HRMARS

- increasing the pace of business activities

- keep growth while getting around bottlenecks

Following are the typical Business Process Outsourcing services that can be found in a collocated data centre.

\section{Contact Centre Services}

Contact Centre Services for BPO is a typical service that unifies multi-channel customer information within a common queue. This service enables customers to connect and participate via the channel of their choice. Customer interactions are managed \& optimized seamlessly throughout every stage of consumer journey and touch points by our flexible Customer Service Solutions. Customer service interactions via are managed by a sustainable, fully / partially outsourced model. The process can be customized according to the client's expectations, ensuring that they foster long-term relationships with expertise in customer experience management.

\section{Social Media Engagement}

BPO Social Media services allows clients to engage and oversee interactions through various social media platforms. Social Media Engagement among others assists in shrinking customer service expenditure, soliciting feedback on products and services and enhancing public opinion of a product or business offering

\section{4/7 Technical Support}

BPO Technical Support services normally delivers Level 1 and Level 2 Technical Support services 24 hours a day, 7 days a week. They offer quick deployment leveraging on organised operational processes, technology and facilities, often by fully trained and experience professionals.

\section{Consultancy and Training}

BPO services also often offer Consultancy and Training services that can be done at the colocation or at client's premises. For example, Lean Six Sigma consultancy assists clients to reduce wastage due to overproduction, underutilisation, defects and redundancies. This will eventually lead to cost optimization, improved quality and value creation. By integrating the tools and processes for Lean Six Sigma, a powerful engine is created to improve quality efficiency and speed in every aspect of business.

\section{Learning and Development Services}

BPO services also deliver training programmes that can develop client's contact centre staff's skills. The training may include customer management, coaching skills, certification programmes and other training through structured learning and development initiatives. The specialized contact centre training aim to help attendees to achieve their excellence in contact centre environment. In the training, the objective is to assist the team achieve their individual goals, group goals, and ultimately the company goals. 


\section{Analytics Services}

BPO Business Analytics \& Insights services aid clients in predicting, managing and mitigating risk in a customer-centric and cost-effective manner that will make the difference between success and failure. Dashboard Reporting offers insights into the critical practices and technologies that are transforming businesses into more informed decision making and better results. Social media analytics facilitates the practice of gathering data and analysing those data to translate into business decisions.

\section{The Business Benefits of Colocation}

More and more companies are moving their operations from in-house server rooms to colocation facilities. This is due to the fact that colocation offers enterprises the ability to meet business demands at a reduced expenditure. While there were factors supporting the original benefit of running their own server rooms, many are finding the advantages of a colocation solution, especially the savings and higher resilience of a collocated data center. Colocation not only enhance overall IT service levels, but also reduces the expenditure and intricacies of IT management. Colocation providers can be trusted to build, manage and support data centers with accompanying IT infrastructure that many businesses may not be able to groom in-house. This facilitate the organizations to maximize their full potential, across the board, within each business unit.

\section{Secure, Fast, Global Network Connectivity}

By creating network infrastructure internally is often involve high cost. Colocation data centers are certainly connected to multiple providers and utilize extremely large bandwidth pipes so that global connectivity is achieved quickly, securely and cost-effectively. It also can reduce the businesses cost to get the better solution.

\section{Access to Technical Expertise and Support}

In-house Network Operations Centre (NOC) with help of remote hands service 24/7/365, allows IT administrators to call for assistance from experts in the data centre. It provides the peace of mind, and also serve to help IT departments realize and considerable savings in budget, time and resources. With this service internal members of staff don't have to physically visit the data centre to take the appropriate action. The colocation provider's will closely monitor and control all network activity to afford absolute availability.

\section{All Security Provisioning Satisfied}

Colocation providers always boast an extensive range of security measures to prevent unauthorized access on a physical level with cabinet locks and constant surveillance by CCTV cameras. This security solution that is most likely better than what could be achieved with an in-house server room. The buildings are built to withstand fires and feature secondary security features designed to prohibit unauthorized access to the data centre. 


\section{Better Disaster Recovery and Business Continuity}

Every business needs to have an effective disaster recovery (DR) plan to protect against unforeseen events that can cripple the IT infrastructure which modern businesses rely on. The critical mission is to safe the hardware from the effects of natural and human-made disasters is crucial. The whole point of a disaster recovery plan is returning business operations to normal after a disaster. Colocation facilities provide better business continuity and disaster recovery services to businesses

\section{Cooling and Power Redundancy}

The goal of any efficient data center is to meet the cooling needs of the computing equipment and facility, by maintaining a constant temperature and ensuring that humidity levels are regulated. Accordance with ASHRAE guidelines, the suitable HVAC systems is used to maintaining an environment. Colocation facilities, boast more power-per-square foot ratios than private data centers. Colocation provider not only utilize uninterruptible power supplies and back them up with diesel-powered generators, to creates total redundancy and allows an organization to benefit from $100 \%$ powered uptime.

\section{Reliability and Uptime}

Colocation facilities consent businesses to realize increased uptime and total network reliability. redundant power solutions and constant on-site monitoring is costly to maintain in house. Businesses can have their network switched over redundancy internet connection. Reliability and uptime keep an organization on the cutting edge of innovation and competitiveness.

\section{Scalability and Room for Growth}

Colocation providers built their facilities to accommodate their customers as their businesses grow. IT infrastructure expansion is a continuous process, so that the decisions need to be made with future planning firmly in mind. That not only physical space but also network bandwidth requirements. The capability to add or remove bandwidth in-house is difficult to achieve and takes time but in colocation solutions the facilitate bandwidth changes in hours by paying for the service is another significant benefit of utilizing a colocation solution.

\section{Quickly Become Compliant}

The certifications enable data centres to keep up with the quick and ever-changing trends in technology. As new or innovative technology enters the market, new legislation, codes of conduct, and more competition urges data centre owners and operators to make sure they have data centres that is in compliance. Colocation providers must renew these certifications annually to remain complaint and ensure their internal controls remain at the highest levels of regulatory standards

\section{Closer to Markets}

To optimize networking capabilities and data storage solutions, customers or target prospects will choose a colocation facility that is located close to their organisation. While physical distance does not have the latency effects, by staying closer to the customer its will reduce network costs and complexity of data transfer across boundaries. 


\section{Reduced Costs Overall}

By reducing infrastructure deployment, management and maintenance costs that the biggest contributing factor to this is the economies of scale that a business can leverage by using a colocation facility. The overall cost saving can be channel e elsewhere to complement core business activities. It's because of colocation service already provided full power redundancy and adequate cooling that is highly cost to the business. The business only pays for the services they use means there is no money wasted on unnecessary products and services.

\section{Buying Criteria and Vetting Process}

The decision in choosing a colocation provider, the organization need to conduct a diligence and compiling a definitive list of buying criteria beforehand it is very importance. To ensure that organization get the colocation solution that is right for their business, deciding exactly what is the top-level business goals for a colocation strategy are very important before having a conversation or discussion with the provider.

\section{Geography/Proximity}

Data centres might be local, but applications are inherently global. Some of the customer choose to have the colocation facilities close to their business. Furthermore, locating colocation infrastructure closer to the customers allows you to scale your IT objectives to departmental business goals more easily in the future. For disaster recovery and business continuity purposes, a colocation facility further away from the organisation's headquarters is often a sensible option. No matter how, many organisations often choose a colocation facility that is close by.

\section{Regulatory/Governance Requirements}

The governance legal and regulatory compliance challenges have become a universal issue. Businesses need to understand any regulatory considerations associated with a data centre located in a specific geographic region. Business have to do some research in term in terms of the political stability of in a specific geographic region when choosing a colocation facility.

\section{Audits}

There are a number of data centre certification standards and best practices that colocation customers should understand in order to ensure the ideal performance of their data centre facility. Colocation facility provider be able to display that it is in adherence to these industry-wide certifications, SSAE 16, CSAE 3416, and ISAE 3402 standards as a minimum. Colocation facility provider must have independent annual audits to ensure ongoing compliance.

\section{Technical Support}

Technical support requires dedicated and experienced team who will work round the clock to deliver higher value to customers which require resources and expertise to maintain in-house. Some colocation providers offer remote hands, which can be used when there is a requirement to quickly reboot a server, to implement a migration plan or to handle queries and its supported by a qualified 
team. Remote hands remove the necessity to travel to the colocation facility, that shall save time and money.

\section{Security}

Colocation facility, security system with $24 / 7$ monitoring and anti-passback that has been installed in the data centre that affords a certain level of contentment. The building also boasts a constant security presence and utilises video surveillance with monitor the 360-degree data centre environment. Colocation facility has been equipped with fire safety and protection systems in place to prevent any equipment being damaged either as the result of an accident or a malicious.

\section{Power Density Capabilities}

Power system in data center facilities has become a critical requirement. The power consumption has risen and will increase from time to time. A high power density will greatly complement your organization's expanding needs and ensure that your infrastructure gets the right amount of power to perform at an optimum level. Colocation facility must have backup. Diesel-powered generators may seem superfluous, but your entire IT stack could end up depending on them if the worst came to the worst.

\section{Service Level Agreements}

Colocation providers have to support their service claims in an official Service Level Agreement (SLA) document. Furthermore, it's not just a $100 \%$ network uptime SLA, but also a 100\% power SLA that provides businesses with the greatest solution. Identify exactly what the provider says they are responsible for, in terms of infrastructure and their associated response times for any failures.

\section{Connectivity}

Organisations want to benefit from superior network speed, resiliency and connectivity, at the best possible price. The diversity of a facility could impact the cost passed onto its customers and so understanding the full connectivity setup and associated costs beforehand is a must.

\section{Interconnectivity}

The capability to connect to different types of environments and other facilities from their colocation site is importance to the business. A colocation provider that allows secure, efficient and affordable interconnectivity via managed 'meet-me-rooms' or other solutions, could allow organizational business to realize more benefits overall.

\section{Amenities}

Data centre colocation providers often differentiate themselves by offering value-added services. The best solutions provide several on-site amenities. It is important to assess the amenities available and understand how they can be used by organizational members of staff. These amenities include offices and work stations, conference rooms and access to phones, copy machines, and fax machines. 
INTERNATIONAL JOURNAL OF ACADEMIC RESEARCH IN BUSINESS AND SOCIAL SCIENCES Vol. 9, No. 6, June, 2019, E-ISSN: 2222-6990 @ 2019 HRMARS

\section{Data Centre Services Market Forecast}

Frost and Sullivan (2017) estimates the Asia-Pacific data center services market to grow at a compound annual growth rate (CAGR) of 14.7\% from 2015-2022 to reach USD\$31.95 billion at the end of 2022.

The main focus driving growth across Asia-Pacific is the explosive digital needs of emerging economies with huge populations. Enterprises are encouraged to look into adopting third-party data centre services, brought about by increasing complexities within the IT infrastructure due to virtualization and consolidation, coupled with various cost constraints. This fact is stimulating the strong growth of managed hosting, especially across emerging economies. Colocation services continue to dominate data centre services revenue currently, even when there is a bigger adoption of managed hosting services. These are clients who require stringent data confidentiality and comprehensive management control of their operations; especially large enterprises and highly regulated vertical markets, e.g. Banking, Financial Services, and Insurance (BFSI). Furthermore, cloud service providers are also creating new demand for colocation as they opt for third-party facilities to host their infrastructure for providing services to customers.

However, some enterprises have chosen to bypass management of their IT operations straight to cloud services such as Infrastructure-as-a-Service (laaS). This causes an adverse outcome to the outsourced hosting market, which resulting in many service providers expanding their data centre service offerings to include cloud-based offerings as well.

The Asia-Pacific data centre services scene is dominated by telecommunications companies/carriers such as NTT Communications (Japan), China Telecom (China), Singtel (Singapore), and Telstra (Australia). They own the core network infrastructure, which lets them to have full control over their services - from an IT service delivery as well as from a connectivity viewpoint. This enables them to benefit from the capacity to offer an end-to-end proposition to clients comprising data centre services, connectivity, cloud offerings, and value-added services such as managed security and disaster recovery, among others. The data centre landscape is also highly fragmented in some countries, as increasing data sovereignty concerns have given rise to dominating vendors. These vendors include Telkomsigma (Indonesia), AIMS (Malaysia), VADS (Malaysia), and Telin (Indonesia).

\section{Challenges to Colocation Providers from Public Cloud}

Enterprises are seen moving from in-house data centers to outsourced data centers in order to save costs and consolidate their IT operations. In the immediate future, large data-centre providers will benefit from demand for co-location space from public-cloud providers. However, it can be seen that data-centre supply is exceeding demand in mature markets like Hong Kong, Singapore and Malaysia. Smaller retail co-location players may find this a battle in the wake of oversupply. Rising public-cloud adoption in these markets may favour large co-location players with direct connectivity to multiple cloud providers. Enterprises want private connections to public cloud for security, performance, and cost reasons. Large co-location providers have the ability to connect enterprises to multiple cloud providers on-demand and simultaneously. A single cloud provider will not be able to provide all the necessary services. 
Telco based co-location and private-cloud businesses in the US are reported to be exploring leaving the data-centre business entirely. There are three key concerns for Telcos:

1. Operating a co-location business regularly conflicts with their private-cloud business. Many colocation clients prefer access to the public-cloud services while the operator continue to push their own private-cloud services.

2. Operating a data-centre business is costly and Telcos are often committed to paying out high dividends to their shareholders. Selling off the data-centre business may assist maintain some needed cashflow. Funds freed from data centre operations can diverted to enable cloud services or be invested in high-growth areas such as Big Data analytics.

3. Large businesses prefer to use a single data centre provider globally and many telcos are lacking this factor due to their limited geographical presence.

\section{Three Cloud Deployment Models}

Equinix Inc. (2016) define are 3 basic definitions of deployment models for cloud computing:

- Public cloud - IT capacity provided in a multi-tenant platform by a service provider and consumed as a service

- Private cloud - IT capacity operating on owned, dedicated systems (either enterprise or collocated) and accessible via a cloud interface

- Hybrid cloud - a blend of public and private clouds, with the platform to move workloads from one type of cloud to the other

\section{Characteristics of Public Cloud}

The attractiveness of on-demand capacity consumption is obvious. Application developers can change to a just-in-time consumption model instead of capital-intensive infrastructure that takes long lead times for planning and construction. However, this route present itself with several challenges:

- Long-term Expenditure - Total reliance on of public cloud can be very costly.

- Restricted Flexibility - Public cloud players tend to offer pre-defined virtual machine sizes and service offerings that may not perfectly meets your actual needs.

- Opaque Technology - Generally public cloud players do not impart the details of the underlying technology they utilise, which can cause alarm to both developers and auditors.

- Shared Security - In essence, multi-tenant environs pose bigger conceivable risk than private deployments.

\section{Characteristics of Private Clouds}

Similar to public cloud, collocated private cloud computing presents simplified consumption and better flexibility compared to in-premise pure hardware-based deployment. However, it runs on dedicated systems that are owned and managed by a single corporation. Private clouds operate a cloud software stack that encapsulates the hardware into pools of virtual resources. The benefits of private cloud include: 
- Financial Savings - As previously mentioned, public cloud can be very costly for long-term steadystate workloads. When capacity needs are well recognized, it is more cost-effective to run at least the base load portion in a private cloud.

- Increased Flexibility - Owners of a private cloud environs are free to plan virtual systems in any way they desire.

- Technology Clarity - A private cloud owner has complete control and clear knowledge of component hardware and software.

- Better Security - Simply, private clouds are single-owner environments.

\section{Hybrid Cloud - The Combination of Public and Private Cloud}

The blended use of both public and private clouds is often labelled as "hybrid cloud." There is no common characterization of hybrid cloud computing, because every environment is distinctive. For different organisations, it may involve operating certain workloads in a dedicated, private cloud and other operations in a public cloud. Some companies may use Cloud Bursting approach, using their private cloud to supply cost-effective base capabilities and bursting into the public cloud for high load or unusual demand conditions. Amongst others, companies may deploy a layered cloud design, operating some portions of a single application stack on physical hardware and others in the public cloud. The ultimate aims of hybrid cloud are to balance control, cost and performance for effective service, whichever approach is chosen.

\section{The Need for Remote-Based Computing Services}

With the advancement of technology and businesses expanding every and each year, owning a private data centre becoming harder to address. These factors have led to the increase of technology cost, staff and process overheads.

To add to the situation, the uncertainties of current economic situation also change business model and how IT technical support units cope with the transformations. IT department is inherently under pressure to create and develop standardised processes, reduce costs and flexibility, all whilst increasing service levels. These factors influence company transformation and the approach IT infrastructure is operated, consumed and built. IT managers are now looking to build SPI (SaaS, PaaS, laaS) delivery models and adopt the hybrid cloud computing. The SPI model helps IT departments bring the scalability and flexibility to their business needs.

More companies nowadays are eager to introduce remote services as a part of their offering because it's been proven to be effective and less cost involvement. For starters, cloud-based remote services make the company more appealing to a wider pool of talented people.

\section{Cloud Computing Model for Enhanced Productivity}

Using the cloud for productivity gives the company the full control over what they want their people to work on and view. Segmenting it into dedicated teams that work together will reduce unnecessary tasking and channel noise while increasing the work output. Cloud computing offer the end user the infrastructure, applications and services to be consumed and charged them at somewhat reasonable 
and affordable price with the complete cloud service management without any need for the users to manage the cloud themselves.

\section{Infrastructure-as- a-Service (laaS)}

By setting the technology base on infrastructure as a service is an advantage for the company. Some mid-sized companies are trying to compete with larger company on customer service but still unable to afford the necessary on-site IT infrastructure (Claranet white paper, 2016). Infrastructures as a Service (laaS) are also known as Cloud infrastructure services. laaS is fully self-service for accessing and monitoring storage, server, networking resource and other service. (Stephen Watts, 2017). It also allows user to purchase resource on demand as needed instead of to buy the hardware outright. laaS used Virtual Machines (VMs) to house data instead of physical servers

\section{Platform-as-a-Service (PaaS)}

Platform as a Service (PaaS), they can develop they own application using programming language, makes the development, testing, and deployment of applications simple, cost-effective and quick. With this technology, the third-party provider, can manage servers, storage, networking and the PaaS software itself. Developers, however, only manage the applications (Fujitsu ,2011). PaaS platform did not authorize user to control or manage the servers, operating system, storage space and other component, its limit only adjustment related to software transfer and configuration setting.

\section{Software-as-a-Service (SaaS)}

Software as a Service (SaaS) represent the largest cloud in the market and its growing rapidly. The advantage of the SaaS, is that the user doesn't have to purchase the hardware and also, they don't have to invest in high viability or security solutions. All infrastructure and performance requirements that related with the cloud infrastructure provider, whose business and core expertise are the delivery of software services are defined in the service level agreement or SLA (Fujitsu, 2011). The third-party vendor used the web to deliver the application to the clients and the client can accessed the web browser without any installations required, although some of it require plugins.

\section{Growth of Cloud Computing Services}

As time goes by and with the growth in cloud computing, infrastructure service eventually will become software services. Then the boundary between software, infrastructure and platform does not matter to the customer anymore as it is only a service. Cloud computing will dominate the modern market by providing the disparate approaches and company can access the infrastructure and resource on demand as a service. Its allow user to focus on their core business without hassle rather than manage the infrastructure.

By empowering and speed up the processing power, memory networking, security and storage, more third-party company will look for the solution in cloud computing with trust. Cloud computing simplified IT management and IT infrastructure, remote access affectively anywhere with the cost efficiency that cloud computing brings about. 
Companies now start to realize the benefit of the cloud computing and investment. We predict that in the next few years, there shall be an increase in adoption of cloud computing services years when the majority of large and medium scaled organization implement the cloud computing strategies within their business.

Security issues have quickly risen to become major concerns for many companies. $50 \%$ of small and midsized organizations reported suffering at least one cyber-attack in the last 12 months (Continuity Centres, 2018)

The trend now is to reduce the hardware on premise but there are some users who believe they need some of infrastructure in their current environment, mainly to control the implementation, data and security.

Somehow User still need the effective solution form of prevention and encryption, by putting the data in the cloud user is in the right direction. The data is store on the specially designed facility with a protection by the latest firewall and anti-malware and cloud provider guarantees security of your data. With all these features data become harder for hacker to break it. The necessity to secure the data is still in user hand, they have to secure their own network and other device while connect to the data.

\section{Outlook into Interconnected Business Ecosystem}

In the colocation data center, the interconnection of multiple clouds, service providers, customers and/or network service providers presents an opportunity for easier integration of services and business processes. Taken as such, interconnection can be a key element of enterprise IT strategy, yet the options and approaches are not always clearly understood.

Enterprises of all kinds continue to move toward consumption of IT in an on-demand model, whether from public or private cloud, or a combination of both. The network is a critical element of this computing paradigm in terms of performance, availability and security. Trends in the adoption of cloud computing and the types of applications being moved to the cloud are already having an impact on network performance; the current surge of interest in microservices and container technology will only serve to increase network traffic further.

There is an evolving set of solutions for network connectivity into and within the data center environment that can help address these networking issues. Some enterprises, for instance, are in the early stages of using cloud-exchange services or a direct-connect service to move their data to and from cloud providers without going over the public internet. However, many enterprises do not yet understand how to adapt their network architectures to the hybrid cloud era.

The data center will be the place where the physical meets the virtual, where clouds and customers connect via networks. We believe interconnection, peering, and 'cloud' networking strategies in the data center will become integral to the overall enterprise IT architecture. As applications - or whole 
business functions - are migrated to cloud, enterprises will use multiple cloud services and environments, often in 'hybrid cloud' configurations, where multiple clouds are integrated to deliver a single application or user experience.

The value of an interconnection 'ecosystem' is growing and is already very large for companies in particular sectors, e.g., where groups of companies need to share large data sets (oil and gas, movie production, pharmaceuticals and genomics), or need to trade information (financial services trading ecosystems). As more firms start to compute and share large data sets, demand for these communal meeting points (data centers) will continue to grow.

\section{Conclusion}

Hybrid cloud is seeing growth better than public clouds. Several businesses that have current privatecloud infrastructure have been using public cloud for newer applications and projects. These companies enjoy the cost savings and flexibility of public-cloud services, nevertheless they continue to keep their most sensitive operations on their private-cloud platforms. The shift is a progression, with private cloud platforms continuing to be strategic components of enterprise IT systems due to various reasons including regulatory issue and autonomy.

Private-cloud providers are adopting third-party cloud management services in preparation for hybrid cloud. In the face of slower growth in private cloud, cloud-service players are now seeking to benefit from the growth in managed third-party cloud services. Clients who now is already subscribing to private-cloud services from these providers shall be able to buy public-cloud services by simply expanding their remaining service agreements.

Global retail co-location providers offer cloud players with a global footprint to expand their ventures and effortless approach to many enterprises that co-locate on these data centers. Many global companies would rather to use a single global co-location provider to serve different regions. Global co-location providers are gaining from this virtuous loop through which cloud players and enterprise players can work together on a single platform.

Hybrid clouds do however, create a number of challenges for enterprises. The private cloud needs to network and move data within multiple public clouds systems. These transmissions must be secure and encrypted. The companies need to put in place policies to control sensitive pieces of data that should not be transferred from private clouds. Likewise, matters such as data integrity and access rights for data must be monitored. In addition, costs relating to operating hybrid clouds will become more complex, with a mix of public cloud and private utilization.

\section{Acknowledgement}

This paper was partially funded by:

1. Conference Support Fund, Institute of Graduate Studies (IPSis, UiTM)

2. Management Fund, Faculty of Information Management, UiTM 


\section{References}

1. Frost \& Sullivan (2017), Asia-Pacific Data Center Service Providers, Frost \& Sullivan Research

2. Equinix Inc. (2016), Application Performance A Framework for Cloud Enablement, Equinix White Paper, retrieved from https://www.equinix.nl/resources/whitepapers/application-performanceframework-for-cloud-enablement/

3. Kimmel, J. (2015), Getting A Piece of Business Process Outsourcing, retrieved from https://www.forbes.com/sites/greatspeculations/2015/06/22/getting-a-piece-of-businessprocess-outsourcing/\#457400c92a64

4. Claranet (2016), White Paper the Business Case for Cloud Computing

5. Fujitsu (2011), White Paper SaaS Business Enablement Services From Fujitsu

6. Watts, S. (September 22, 2017), SaaS vs PaaS vs IaaS: What's the Difference and How to Choose

7. Continuity Centers (2018), 5 Ways to Empower Your Business Through the Cloud retrieve from https://continuitycenters.com/cloud-empowered-business/

Corresponding Author: Saiful Farik Mat Yatin. Faculty of Information Management, Universiti Teknologi MARA (UiTM) Selangor, Malaysia 